\title{
Developing a Pollution Measuring System to Manage Demolition Projects Complying with Legal Regulations
}

\author{
Markus Reinhardt ${ }^{1}$, Anna Kühlen ${ }^{2}$, and Shervin Haghsheno ${ }^{3}$
}

\begin{abstract}
Demolition and construction processes usually generate pollutions, namely dust, noise and vibration. These pollutions can have a negative impact on human health or the environment. Hence, pollutions are often a strong argument against necessary demolition and building projects. There are legal regulations of pollution control to minimize these impacts. However, usually no measurements and least of all permanent monitoring are performed on site, as pollution measuring is very costly. Often pollutions are only controlled by goodwill of the contractor, who acts upon his experiences and knowledge. To initiate pollution-reducing actions on site, an inexpensive measuring system is developed, which measures and calculates pollutions in real-time. In this paper, the system is described. First the basic system requirements are introduced. Then the systems components and the system buildup are explained in some detail. The system consists of measurement nodes (usually 6-10), which monitor dust, noise and vibrations. These nodes are supposed to be placed around the construction/deconstruction object. An analyzing unit calculates the estimated level of pollution in every important position. The calculated data is sent directly to the operator, since the excavator usually causes major emissions and resulting pollutions can be reduced by adjusting the working process, such as choosing a proper demolition technique or applying pollution protection measures. The aim of this research is to help the contractor and principal to perform construction and demolition work complying with legal regulations by warning them, when limits are exceeded.
\end{abstract}

Keywords: Demolition projects, dust, noise, pollution control, vibration.

\section{Introduction}

Reports (WHO 2011, WHO 2013) of negative influences on human health caused by pollutions, such as dust and noise, are continuously raising public awareness. Especially, when these pollutions are caused by construction or demolition works in the neighborhood, citizens often try to force authorities to control these actions and to assure compliance with pollution limits (TALuft, TALärm, DIN 4150-2, DIN 4150-3). Related constraints can sometimes even hinder construction or demolition works. A system, which allows continual measurement and control of pollutions, might help to guarantee that limits are met and works can be performed without obstructions. Such a system is not primarily meant to increase labor protection (Lunts 2013), but to reduce impacts on the local environment.

\footnotetext{
${ }^{1}$ Research Associate, Institute for Technology and Management in Construction (TMB), Karlsruhe Institute of Technology (KIT), Kaiserstrasse 12, 76131 Karlsruhe, Germany, Tel: +49-721-608-48265, E-mail: markus.reinhardt@kit.edu

${ }^{2}$ Research Associate, French-German Institute for Environmental Research (DFIU), Karlsruhe Institute of Technology (KIT), Hertzstrasse 16, 76187 Karlsruhe, Germany, Tel: +49-721-60844691, E-mail: anna.kuehlen@kit.edu

${ }^{3}$ Professor, Institute for Technology and Management in Construction (TMB), Karlsruhe Institute of Technology (KIT), Kaiserstrasse 12, 76131 Karlsruhe, Germany, Tel: +49-721-608-42646, E-mail: shervin.haghsheno@kit.edu
} 
To allow contractors and principals to perform construction and demolition works within these pollution limits, the Karlsruhe Institute of Technology (KIT) developed an Immission Measurement System (IMS) that continuously monitors the important local pollutions, dust, noise and vibration (Kühlen et al. 2014). This system measures all these important pollutions nearly in real-time. It informs stakeholders about the actual pollution situation on/around site and alerts them, when set limitations are exceeded. Hence, the contractor can take action, such as using counter measures, to comply with regulations. The main purpose of this system is to meet the demands of all major stakeholders in construction and demolition works:

- Residents: No dangerous pollution levels (WHO 2011, WHO 2013) are released during the execution of construction/demolition works.

- Authorities: The regulations (TALuft, TALärm, DIN 4150-2, DIN 4150-3) are met during the execution of construction/demolition works.

- Principal: The construction/demolition work is affordable.

- Contractor: The construction/demolition work can be realized.

The system, including its single components and its implementation in practice, is described in this paper. First, approaches related to the topic in recent research are reviewed. Then the basic pollutions are described and requirements for the system are defined. The chosen sensors for this system and the tests to prove their performance are stated. The buildup of the system and the benefit for any stakeholder are described. Finally the paper is concluded by outlining required future research in this topic.

\section{State-of-the-Art of Science and Technology}

In demolition and building projects, there is usually no measurement of any pollution on the construction site. Only occasionally, at important or very exposed construction sites, measurements are done. But the measurement results are regularly not used to improve the situation instantly. Furthermore, usually the validity of the results is limited, as for instance, according to a guidance to control dust emissions from construction and demolition in London (GLA 2006), even in high risk environments just two automatic particulate monitors are demanded on site.

The systems generally applied in these cases are very expensive devices. Therefore, they are used rarely and deliver only punctual measurement results (DIN 4150-2, TALuft, TALärm), which cannot be taken to estimate the complete pollution distribution in the area. Often the proposed systems cannot be used to get information in real time, like sampling cassettes for dust (Kühlen et al. 2014). The focus of these rarely applied measurement systems is the support of authorities in identifying hazards or problems for any stakeholders involved in construction/deconstruction projects. Within this content authorities mainly take the gathered data to identify violations of limits ex post. Hence, it is not possible to influence construction work in real time in order to meet the regulations.

To date the best method to reduce and control pollutions caused by construction/demolition works is the prediction and pre-evaluation of possible pollutions by computer-based models before the actual work on site. Examples of such computerbased models used in Germany are SoundPLAN ${ }^{4}$ to calculate the distribution of noise (SoundPlan Acoutstics) and dust (SoundPlan Air Pollution) or Austal2000 5 to estimated dust propagation. And there are prototype algorithms to predict vibration propagation like BP-ANN (Armaghani, 2013). But without pollution control by a system allowing extensive

\footnotetext{
${ }^{4} \mathrm{http}: / /$ www.soundplan.eu/english

${ }^{5}$ http://www.austal2000.de/en/home.html
} 
measurements on the real site, the model results cannot be validated and controlled.

The review shows that up to now there is a lack of measurement systems and respective research for their implementation in construction and deconstruction works for sufficient pollution control on site. There is no system known to the authors, which allows the integral monitoring of noise, dust and vibration on construction and demolition sites in real time and which supports the contractor in the adjustment of working processes and the application of counter measures to work in accordance with the regulations.

The IMS system introduced in this paper and described in detail in the following should help to improve the knowledge of pollution control on construction/deconstruction sites. At the moment the IMS is developed and tested applied to deconstruction works. In combination with a support system (cf. Kühlen et al. 2014) here the IMS is supposed to provide solutions for choosing the best practices for demolition to efficiently demolish any building while meeting the limits set by regulation. The focal application of the IMS is the monitoring of the three most common pollutions on construction/demolition sites, namely noise, dust and vibration, in real time to support the contractor to do his work within the regulatory limits. The IMS is planned as a low cost system, which uses many measurement nodes to estimate the complete distribution of noise, vibration and dust in the affected area in nearly real time as good as possible.

\section{Characterization of Relevant Pollutions in This Research}

In the following, noise, dust and vibration pollutions and their characteristics within this research are described.

\section{Dust}

Dust basically consists of small, solid particles with a higher density than air, but which float in the air. Dust always existed in the air, for instance in the form of sand, volcanic ashes and pollen. But especially in rural areas, there is a great amount of dust, caused by different anthropogenic sources, including dust from organic materials, soot and brake dust. In this research mineral dust resulting from construction/deconstruction works is relevant. There are more criteria to define dust besides the type of material. Due to the effect of dust to human health the particle size is very important. Particles larger than $10 \mu \mathrm{m}$ are supposed to be of no harm to humans organisms, because they are too large for inhaling. Usually dust of this size is heavy and tends to deposit soon. Furthermore, particles smaller than $0.1 \mu \mathrm{m}$ are not considered as critical to human health, as the body can exhale them (WHO 2011).

\section{Noise}

Noise is basically a vibration that compresses air. The larger the amplitude, the difference between compressed and uncompressed air, the higher is the sound level. Beside the sound level, the frequency influences the felt loudness by humans (Maue et al. 2003). The human ear is more sensitive to frequencies around $1.000 \mathrm{~Hz}$ to $10.000 \mathrm{~Hz}$. To consider this influence of frequency, weightings like the A-, B-, C.- or D-weighting are introduced to define the level of noise. Nowadays most commonly used is the A-weighting, especially for any measurement of industrial or environmental noise.

\section{Vibration}

Like noise, vibration is defined by frequency and amplitude. But vibration uses the ground and other solid material as basic transmitting medium (not air as noise does). Vibrations with frequencies usually between $0,1 \mathrm{~Hz}$ and $50 \mathrm{~Hz}$ can be dangerous to human health and 
can cause damages to buildings (DIN 4150-2, DIN 4150-3). Main sources of vibration monitored by the IMS are falling objects or large machinery, like trucks or excavators.

\section{Basic System Requirements}

There are some basic requirements for the use of the IMS on site. First, the system has to be cheap to allow its operation on any construction/demolition site. At the moment costs for single measurements are usually very high, as the costs of the equipment and for the required efforts to use these devices are high. Therefore, it is not affordable for regular construction works. Secondly, pollution levels should be measured at diverse locations at the same time to map the pollution situation appropriately. For instance, to estimate the pollution situation of a small construction site adequately, the pollutions at least at six locations should be measured. Current measurements are often performed only at one location (TALuft, TALärm, DIN 4150-2, DIN 4150-3) on/close to the site. Furthermore, to gain a complete picture of the pollution situation over time, thirdly, the system should allow permanent monitoring of the relevant pollutions. Finally, the system must be intuitive in use and able to measure in every condition. It has to be easily maintained and set up in any situation, so it can be done by the regular personal on site. In the following the single components of the IMS and the concept of the system to measure pollutions are described.

\section{System Components and Pollution Measuring Concept}

The IMS consists of several nodes (MK for German MessKnoten in Figure 1), whereas one node represents one measuring location. In each node sensors for the different pollutions, dust, noise and vibration, are combined. The electro-technic aspects of the nodes and of the receiver are not in the focus of this paper. They are described in detail in Gaedeke et al. (2014).

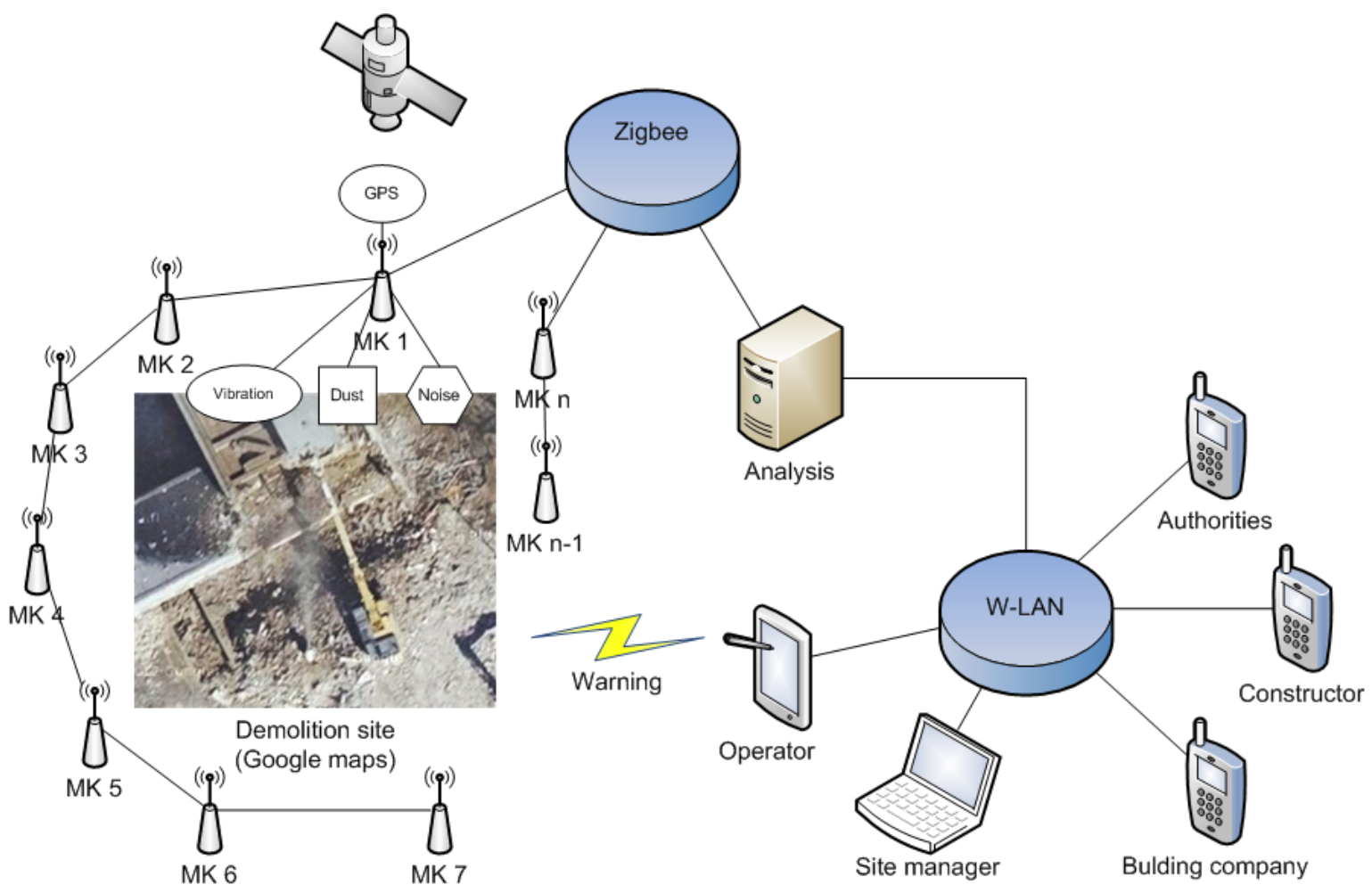

Figure 1. Complete IMS on a construction site 
The wireless connection is built on a self organizing network on ZigBee basis. This leads to a stable system with far reach. Furthermore batteries and a GPS sensor are integrated.

\section{Overall System}

The IMS system has to encompass at least six measurement nodes to be able to map the pollutions of a complete area. A Server with a receiver for the ZigBee network is used to gather, analyze and save all data (Figure 1). Besides managing data, the server generates alerts when impact levels are exceeded. The server itself is part of a Wireless LAN or even GPRS, to submit the data to any interested and authorized stakeholder. A portable device should be integrated into any equipment, e.g. excavators, where usually the major polluting actions of the construction/deconstruction site are controlled.

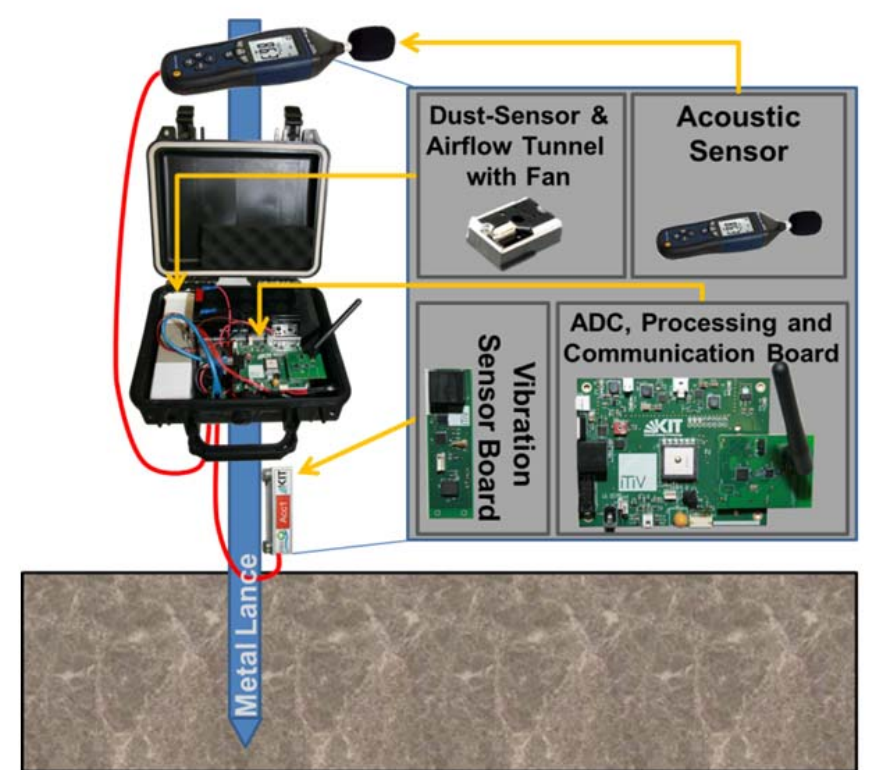

Figure 2: Elements of a single sensor node (Gaedeke et al. 2014)

\section{Dust Measuring}

The IMS uses a cheap Compact Optical Dust Sensor GP2Y1010AU (2005) from Sharp to measure dust (Figure 2). The sensor uses an infrared diode to transmit light for the detection of dust particles in the air. The dust particles reflect light, which is transformed by a phototransistor into an electric current. This current is converted into the amount of dust in the air $\left[\mathrm{mg} / \mathrm{m}^{3}\right]$. To achieve a continuously air flow through the sensor, it is installed in a vent pipe together with a small fan. As shown in Figure 3, the system parameters are tested versus other commercial dust measurement systems (e.g. Casella CEL-712 Microdust Pro (CEL-712)).

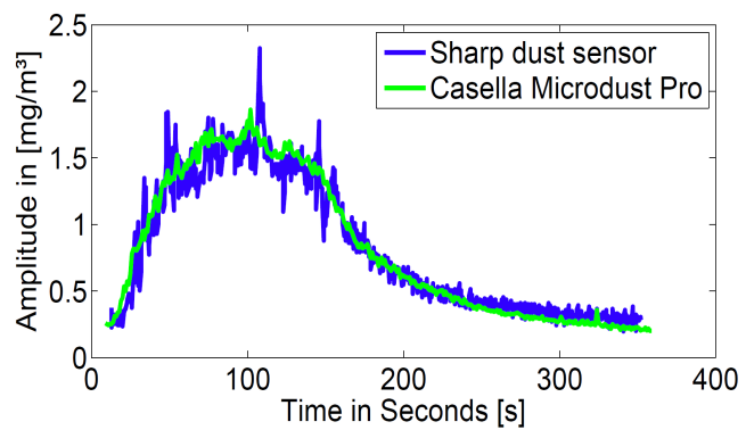

Figure 2. Test of the GP2Y1010AU versus the 
Dust is the most unstable measurement, as it is highly influenced by weather and other factors of the local surrounding. To measure dust as good as possible, the system uses multiple measurement points and includes weather data, especially wind. The position of the measurement points is automatically determined by GPS. The overall dust distribution on/around site is calculated based on the data of position and wind and the different measurement results. It is targeted to estimate the highest anticipated value to check it versus regulation.

\section{Noise measuring}

As noise is distributed through the air, which is a nearly homogenous medium, noise is easier to determine than the other two pollutions measured by the system, dust and vibration. For the determination of noise the commonly A-weighting is used in the IMS. Affecting obstacles can be easily estimated. Therefore, standard class 2 sound level meters PCE-322A (2014) have been integrated in the system that are just connected by an Analog Digital Changer ADC (Figure 2) to every node. The calibration is directly done over the central server by a calibration tool.

Since noise is the best predictable parameter measured by the IMS, the evaluation with the help of the system is very good. A resulting point noise source of the theoretical sound level is calculated (Figure 4) based on the measured noise levels at each location and their position (GPS). From the resulting point source a mapping of the complete sound levels of the whole area is possible. An accuracy of the source point of about $5 \mathrm{~m}$ in any direction and of the sound level of $6 \mathrm{~dB}$ is proven in tests (Figure 5). This is acceptable for a first estimation. Further evaluation of the system is needed to reduce errors and improve results.

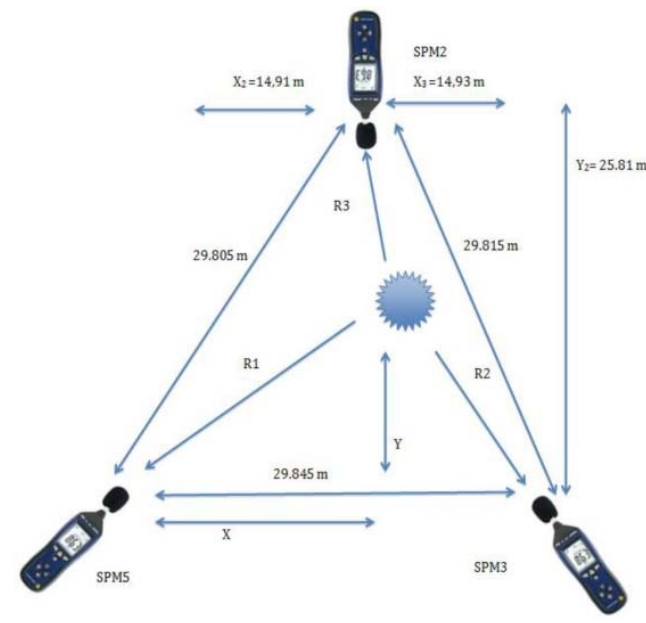

Figure 4. System for calculating the position of the point noise source

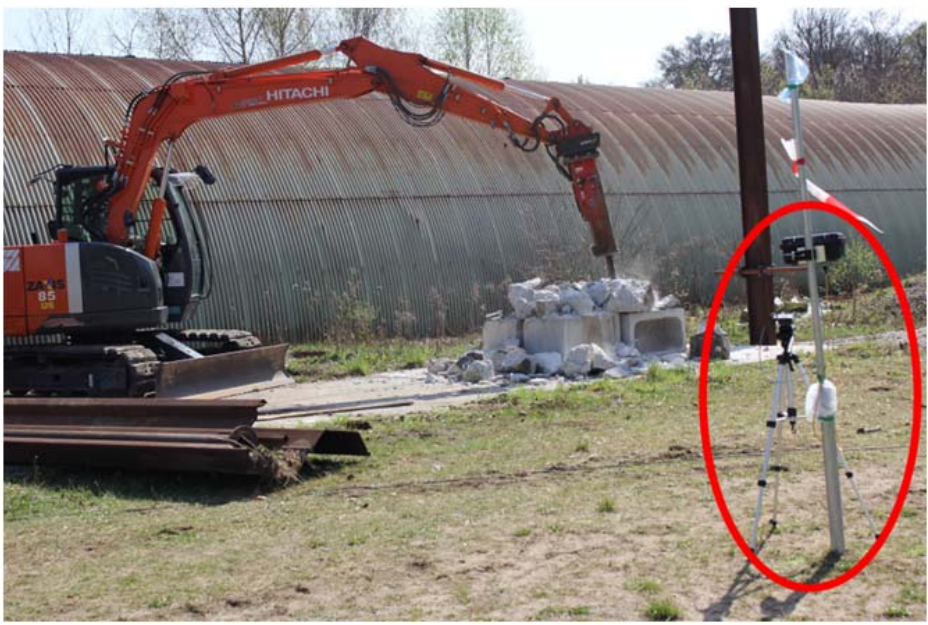

Figure 5. Test site using the IMS for evaluating pollution

\section{Vibration Measuring}

The IMS uses Micro Electrical-Mechanical Sensors (MEMS sensors) from Murata (SCA3100-D04), which determine vibration by acceleration. At each node the sensor is mounted in an earth screw (Figure 2). The screw should be brought into a depth, where the amount of vibration matters, e.g. the depth of the near foundation. The vibrations created by this sensor are quite high, but tests versus the professional system ZEB/SM-3C (2012) suggest that the critical levels can be clearly determined (Figures 6 and 7). 
The transmission of vibration is done through the ground. In homogenous ground conditions, which are seldom in rural areas, the measurement results are very accurate, according to tests with the IMS and the ZEB. These tests showed as well that the MEMS sensors detect exceed of limitations according to DIN 4150-2 and DIN 4150-3. As for noise, the target of these vibration measurements is the identification of the location, where all energy is emitted. From this location the overall pollution on/around site can be calculated. There are already mathematical models to estimate vibration propagation as described in Armaghani (2013). Since different, usually unknown soil layers respond differently related to vibrations and the vibration might be transmitted in a depth that is not monitored, tests prove that it is very hard to calculate the accurate position of the source. Therefore, at the moment vibrations are monitored by identifying the points of interest including their depth. And the discrete vibration values are measured in these points. Hence, the system is applied to measure near to and at the foundation level of buildings, which may be affected by vibration.

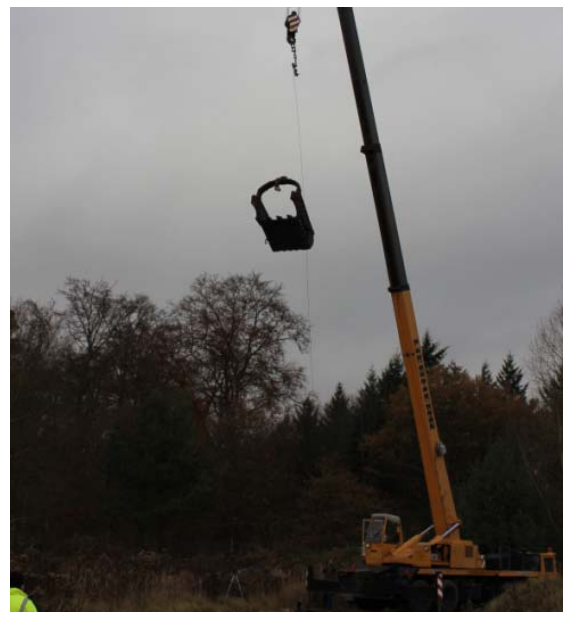

Figure 6. Tests with falling objects

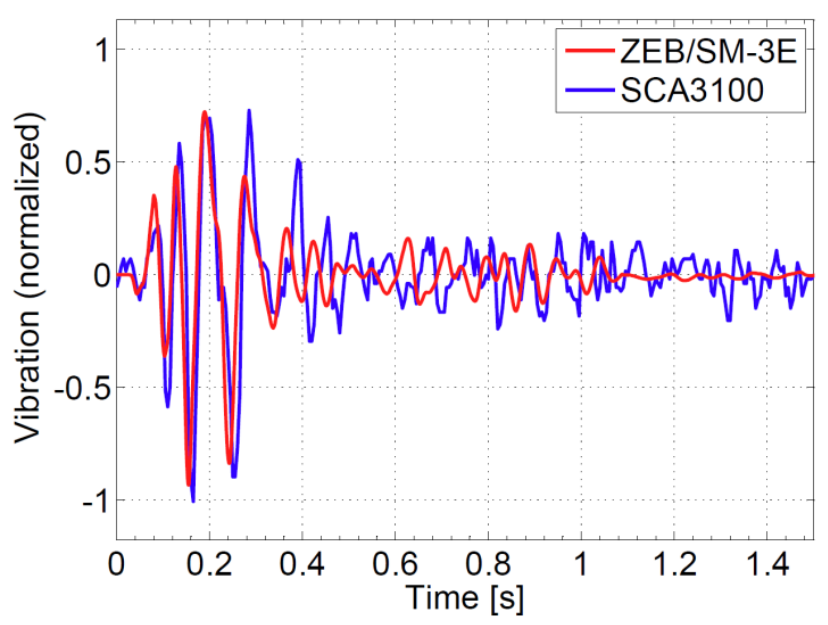

Figure 7. Test of ZEB/SM-3E versus Murata

\section{Build up of the system}

\section{Definition of the points of interest}

There are different considerations by choosing the points of interest for the installation of the measurement nodes. Most obviously it is important to find places/positions for the IMS nodes, where best possible measurement results can be achieved. For dust and noise this is usually done, when there is a clear line of sight. But also adjacent buildings may influence the results. Hence, they have to be considered and adjusted as noise may be reflected by buildings or the wind may be canalized which may lead to high dust levels in certain areas. For vibration it is more difficult to find the right place, since there is usually no way to completely evaluate the ground conditions. Here the best measuring results might be gained by measuring very close to the foundation of any building of interest. Beside the considerations for the best measurement position with minimal influences on the results, there are also operational aspects that have to be taken into account by choosing the points of interest. For example, the system has to be installed in places, where it does not interfere with the construction/deconstruction work and it has to be accessible for a power line or to change batteries. 


\section{Physical build up and setting up the network}

The earth screw with the vibration sensor inside is turned into the ground as shown in Figure 8. Then there is a post mounted on the earth screw. All other devices of one node are then attached to the post (Figure 9). The server has to be placed preferably at a dry and secure place. After all systems are turned on, they establish the self organizing network and start the measurement automatically. Any external device can access the server.

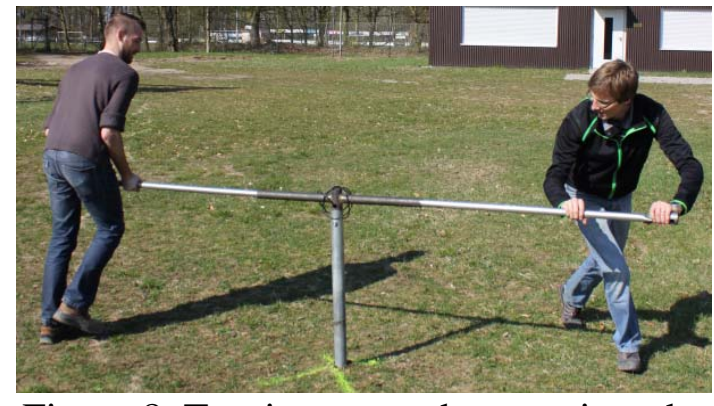

Figure 8. Turning an earth screw into the ground

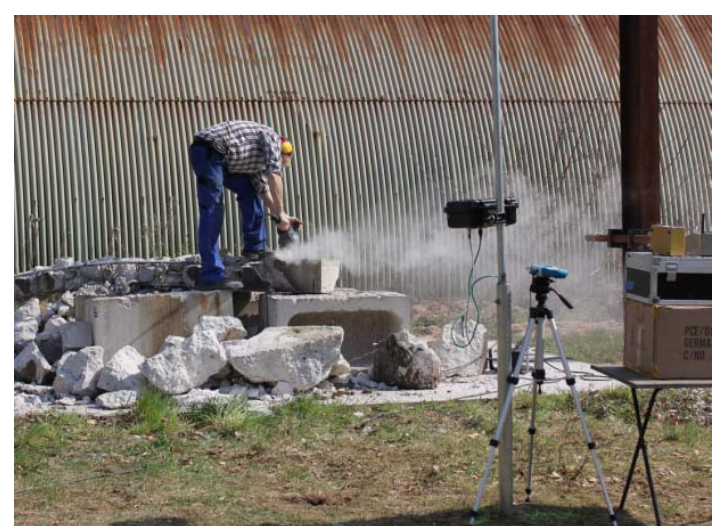

Figure 9. Fully equipped node used in a test

\section{System application and benefits for the different stakeholders}

The system information can be interpreted according to the stakeholder interest. Nevertheless, one conclusion from the system results is most important and the same for all stakeholders. This conclusion refers to the compliance with regulations due to pollution limits. As there is no reason or chance to interfere with other participants, if the regulations are met and this compliance is proven by the system results.

\section{Residents:}

The major target of residents is not to be affected or harmed by any pollution of the construction site. Health is usually the main reason and also related regulations focus on this topic. There is no possibility to act versus construction works, when the regulations are met, which can be proven by the results of the IMS. The second target of residents is not to be disturbed. In this case the system generally cannot prevent being affected by demolition works, but it can help to meet the impact limits set by regulations. Hence, disturbances usually have to be accepted by residents.

\section{Authorities:}

The main target of authorities is taking care that residents and the environment are not affected more than stated in regulations. Authorities are satisfied, when regulations are met, which is proved by the results of the IMS, as mentioned above.

\section{Principal:}

In Germany the principal is responsible for meeting the regulation related to construction works. He usually transfers this duty to the contractor. In general, one major interest of the principal is a cost effective execution of the work. For instance, a delay of the work by authorities' intervention can be very expensive.

\section{Contractor:}

The contractors target is also the major target of the IMS, since this stakeholder benefits most of using the system. The contractor usually agrees to do all work complying with regulations. Therefore, the IMS allows the contractor to adjust his work to the regulations 
most beneficially. He can use additional machinery, when limits are not met. Or he can apply protective measures, when limits are exceeded. The meeting of limits can imply a slower progress for the contractor. For instance, different tools have to be used, work has to be stopped in times with high pollution, passive protective measures, like walls, or active protective measures, such as water cannons, have to be applied. Nevertheless, he is also interested in limited interventions due to his working plan. If the contractor can prove complying with regulations, the chance of work interventions and prohibitions is limited. The IMS can provide a sound legal protection to the contractor.

\section{Conclusion}

The presented IMS is the first integrated monitoring system for construction and demolition, which can be used to meet regulatory limits, related to noise, dust and vibration impacts. The system uses the measured data to calculate the pollution distribution and propagation to warn the contractor and machine operators in real time, when pollutions are too high to comply with legal regulations. The system has been designed and built for the regular use on site. The requirements like low cost sensors, easy to maintain and a secure and stable network are realized.

The IMS helps to meet the demands of all relevant stakeholders of construction and demolition works by meeting the regulations related to noise, dust and vibration pollutions. Additionally, the system can support the cooperation of these stakeholders. For instance, the principal and contractor can guarantee compliance with regulations by applying the system. In case the system will become mandatory for construction/deconstruction works in the future, the principle should be responsible for the application on site. To date the IMS has been successfully tested in laboratory environments which have characteristics of a real construction site. A test on a real demolition site is planned in 2015.

The following basic functions are integrated

A Basic measurement of dust, noise and vibration

A Self connecting network

A Easy set up, easy to maintain

A System to collect and distribute data

All these features are tested on a test site with demolition equipment and are fully operational. Therefore, the system's state corresponds to the Technology Readiness Level 6 (TRL6), which means its serviceability is given. To reach TRL 7, which would imply it is ready for use in real operation, additional functions have to be integrated and tested. Therefore further tests in rural environment under operational conditions have to be done and the integration of an automated dust, noise and vibration analysis for higher accuracy is needed.

\section{References}

Armaghani, D. J., Hajihassani, M., Mohammad, E. T., Marto, A., Noorani, S. A., 2013. Blasting induced flyrock and ground vibration prediction through an expert artificial neural network based on particle swarm optimization. In: Arabian Journal of Geosciences, November 2013.

CEL-712. User Manual, CEL-712 Microdust Pro Real-time Dust Monitor [online]. Available from: http://www.casellasolutions.com/uk/en/document-library/supportdocs/microdust-pro-handbook.pdf [Accessed 1st of September 2014] 
DIN 4150-2, 1999 Standard DIN 4150 1999-06 Erschütterungen im Bauwesen - Teil 2: Einwirkung auf Menschen in Gebäuden

DIN 4150-3, 1999 Standard DIN 4150 1999-02 Erschütterungen im Bauwesen - Teil 3: Einwirkung auf bauliche Anlagen

Gaedeke, T., Hartmann, F., Niestoruk L., Reinhardt M. and Stork W., 2014. Real-time Environmental Emission Monitoring on Construction Sites. unpublished paper for the $6^{\text {th }}$ European Embedded Design in Education and Research Conference 2014, 11-12 September 2014, Milano, Italy

GP2Y1010AU, 2005. Device Specification for Air Quality Sensor GP2Y1010AU [online], Available from: http://www.sharpsme.com/download/GP2Y1010AU-SSpdf [Accessed $1 \mathrm{st}]$

GLA, 2006. The control of dust and emissions from construction and demolition [online], Available from: http://www.london.gov.uk/sites/default/files/archives/mayorenvironment-air_quality-docs-construction-dust-bpg.pdf [Accessed 2nd of October 2014]

Kühlen, A., Stengel, J., Volk, R., Schultmann, F., Reinhardt, M., Schlick, H., Haghsheno, S., Mettke, A., Asmus, S., Harzheim, J., 2014. Minimierung von Umweltbelastungen (Lärm, Staub, Erschütterungen) beim Abbruch von Hoch-/Tiefbauten und Schaffung hochwertiger Recyclingmöglichkeiten für Materialien aus Gebäudeabbruch Endbericht zur 2. Phase des Forschungsprojekts. Gefördert durch die Deutsche Bundesstiftung Umwelt (DBU), unpublished project report, Karlsruhe, August, 2014.

Lunts, A., Urbane, A., Sulojeva, J., Jemeljanovs, V., 2013. Risk reduction possibilities considering equipments, working environment and human factor in road construction. In: Safety of Technogenic Environment, 2013 (5).

Maue, J. H., Hoffmann, H. and von Lüpke, A., 2003. 0 Dezibel plus 0 Dezibel gleich 3 Dezibel. Berlin: Erich Schmidt Verlag

SCA3100-D04. 3-Axis high performance accelerometer with digital SPI interface [online], Available from: http://www.murata.com/en-eu/products/sensor/accel/sca3100 [Accessed 2nd of October 2014]

PCE-322A, 2014. Schallpegelmeter PCE-322A Bedienungsanleitung [online], Available from: $\quad$ https://www.pce-instruments.com/deutsch/slot/1/download/14115/ ba-schallmesser-pce-322-v-1-2-07-2014-de.pdf [Accessed 1st of September 2014]

TALärm, 1998. Technische Anleitung zum Schutz gegen Lärm. Berlin: Bundesministerium für Umwelt, Naturschutz und Reaktorsicherheit

TALuft, 2002. Technische Anleitung zur Reinhaltung der Luft. Berlin: Bundesministerium für Umwelt, Naturschutz und Reaktorsicherheit

WHO, 2011, Burden of disease from environmental noise. Quantification of healthy years lost in Europe. Copenhagen: World Health Organization Regional Office for Europe.

WHO, 2013. Health risk of air pollution in Europe - HRAPIE project. Copenhagen: World Health Organization Regional Office for Europe.

ZEB/SM-3C, 2012. Produktblatt ZEB/SM-3C Schwingungsmessgerät [online]. Available from: $\quad$ http://www.zeb-maxam.com/index.php/de/download/category/18schwingungsmessgeraete?download=51\%3Azebsm-3c-schwingungsmessgeraet

[Accessed 1st of September 2014] 